REVIEW ARTICLE

W.S. Bartynski

\section{Posterior Reversible Encephalopathy Syndrome, Part 1: Fundamental Imaging and Clinical Features}

\begin{abstract}
SUMMARY: Posterior reversible encephalopathy syndrome (PRES) is a neurotoxic state coupled with a unique CT or MR imaging appearance. Recognized in the setting of a number of complex conditions (preeclampsia/eclampsia, allogeneic bone marrow transplantation, organ transplantation, autoimmune disease and high dose chemotherapy) the imaging, clinical and laboratory features of this toxic state are becoming better elucidated. This review summarizes the basic and advanced imaging features of PRES, along with pertinent features of the clinical and laboratory presentation and available histopathology. Many common imaging/clinical/laboratory observations are present among these patients, despite the perception of widely different associated clinical conditions.
\end{abstract}

$I_{\text {in }}^{\mathrm{n}}$ nitially recognized in association with eclampsia, cyclosporine after transplantation, and in the setting of severe hypertension, posterior reversible encephalopathy syndrome (PRES) has become synonymous with a unique pattern of brain vasogenic edema seen in the setting of neurotoxicity. ${ }^{1-14}$ On CT or MR imaging studies, the edema is often widespread but predominates in the parietal and occipital regions, likely leading Hinchey et $\mathrm{al}^{15}$ to suggest the "posterior" description.

A substantial experience with PRES has evolved; and though more widely recognized, controversy still exists as to the mechanism responsible for the brain edema. Specifically, what is the role of hypertension and is the edema related to hyperperfusion or hypoperfusion? In this review, the fundamental clinical and imaging features of PRES will be emphasized with controversial issues to follow.

\section{Imaging Patterns in PRES}

At CT/MR imaging, the brain typically demonstrates focal regions of symmetric hemispheric edema (Fig $1 A,-B$ ). The parietal and occipital lobes are most commonly affected, followed by the frontal lobes, the inferior temporal-occipital junction, and the cerebellum. ${ }^{16-18}$ Lesion confluence may develop as the extent of edema increases. MR diffusion-weighted imaging (DWI) was instrumental in establishing and consistently demonstrating that the areas of abnormality represent vasogenic edema. ${ }^{19-24}$ The edema usually completely reverses.

The basic PRES pattern resembles the brain watershed zones, with the cortex and subcortical and deep white matter involved to varying degrees. ${ }^{12,14,16,25,26}$ Three hemispheric pattern variants may be encountered with similar frequency (holohemispheric [Fig 1], superior frontal sulcal, and primary parietal-occipital). ${ }^{27}$ These demarcate lateral hemispheric blood supply (middle cerebral artery [MCA]) and medial hemispheric supply (anterior cerebral artery [ACA], posterior cerebral artery $[\mathrm{PCA}]$ ) and further reflect the junctional/watershed nature of PRES.

Characteristic lesion locations such as the inferior tempo-

Received and accepted November 5, 2007

From the Department of Radiology, Division of Neuroradiology, University of Pittsburgh, Presbyterian University Hospital, Pittsburgh, Pa.

Please address correspondence to Walter S. Bartynski, MD, Department of Radiology, Division of Neuroradiology, University of Pittsburgh, Presbyterian University Hospital, 200 Lothrop St, D 132, Pittsburgh PA 15213; e-mail: bartynskiws@upmc.edu

DOI 10.3174/ajnr.A0928 ral-occipital junction, superior frontal sulcus, and parietal/ occipital region likely represent junctional expression between second-order branches or distal hemispheric branches. ${ }^{16}$ Linearly oriented focal deep white matter involvement may represent expression of PRES in the deep (intrahemispheric) watershed. ${ }^{27}$ A continuum is noted between diminutive and extensive expression of PRES; and partial, asymmetric, or mixed forms of these patterns may be encountered.

Focal/patchy areas of PRES vasogenic edema may also be seen in the basal ganglia, brain stem, and deep white matter (external/internal capsule). ${ }^{20,27-31}$ When they accompany hemispheric or cerebellar PRES, it is easy to recognize these areas as companion lesions. Present in isolation or when the hemispheric pattern is incompletely expressed (partial/asymmetric), the diagnosis of PRES can be challenging. ${ }^{27,32}$ If cerebellar or brain stem involvement are extensive, hydrocephalus and brain stem compression may occur. ${ }^{33-35}$

Focal areas of restricted diffusion (likely representing infarction or tissue injury with cytotoxic edema) are uncommon $(11 \%-26 \%)$ and may be associated with an adverse outcome. ${ }^{20,21}$ Hemorrhage (focal hematoma, isolated sulcal/subarachnoid blood, or protein) is seen in approximately $15 \%$ of patients. $^{16,27,32}$

\section{Basic Clinical Features of Neurotoxicity with PRES}

Patients at risk for PRES are summarized in the Table. Neurotoxicity with characteristic watershed CT/MR imaging features was initially noted in eclampsia, allogeneic bone marrow transplantation (allo-BMT), solid organ transplantation (SOT), and in association with severe hypertension. With similar clinical/imaging presentation recognized the mid 1990s, additional associations were noted (autoimmune conditions, thrombotic thrombocytopenic purpura, and medical renal disease), and the term "PRES" was introduced. ${ }^{15,20,22}$ PRES is seen with unique or high-dose cancer chemotherapy (Table) and has recently been associated with infection, sepsis, and shock. ${ }^{36}$ Additional considerations have been suggested in numerous case reports as reviewed in the Table.

\section{Clinical/Laboratory Characteristics in PRES}

Clinical symptoms at toxicity are broad but include headache, vision change, paresis, hemianopsia, nausea, and altered mentation. $^{37,38}$ Symptoms may develop over several days or may be recognized only in the acute setting. Generalized seizures 

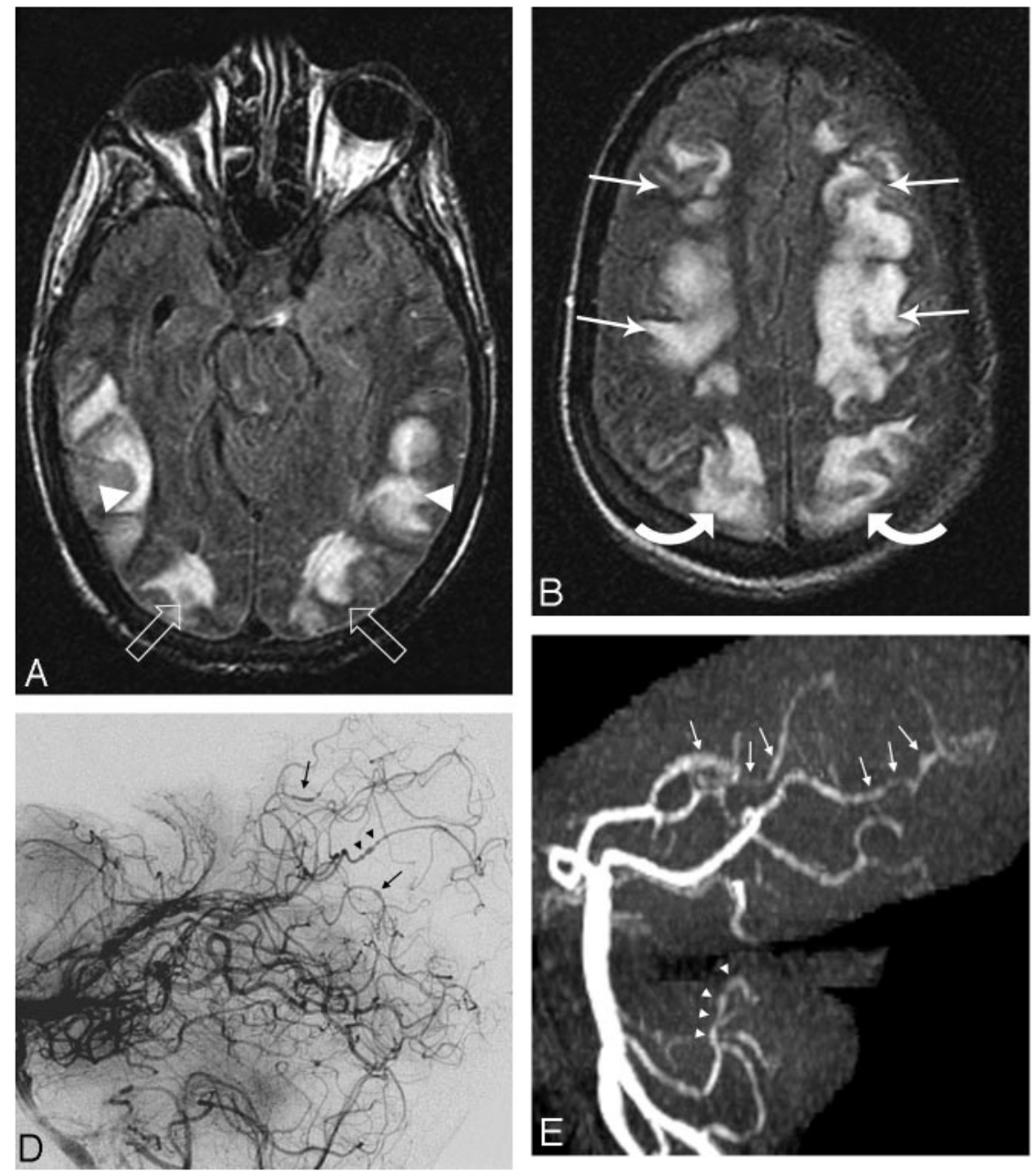

strate areas of focal vasodilation and vasoconstriction in the PCAs bilaterally (arrows), consistent with vasculopathy, similar to the vertebral artery CA appearance. Posterior inferior cerebellar artery (arrowheads) irregularity is also present.

are common and coma may develop. In approximately $70 \%-$ $80 \%$ of patients, moderate-to-severe hypertension is observed. Toxicity blood pressure is normal or only minimally elevated in $20 \%-30 \%$ of patients in eclampsia, allo-BMT, and most large reported PRES series. ${ }^{11,15,17,22,27,39-42}$

Best studied in preeclampsia/eclampsia, laboratory evidence of endothelial injury is often present with platelet consumption (thrombocytopenia) and evidence of red cell fragmentation (schistocyte formation, increase in lactate dehydrogenase $[\mathrm{LDH}]) .{ }^{43,44}$ Developing hypertension in preeclampsia is related to systemic vasoconstriction with accompanying reduced intravascular volume and hemoconcentration. Renal dysfunction with proteinuria and hypomagnesemia occur; systemic edema develops due to a combination of altered endothelial function and reduced oncotic pressure. Hepatic ischemia may lead to liver dysfunction and, when severe, hemolysis, elevated liver enzymes, and low platelets (HELLP) syndrome.

In infection/sepsis/shock-associated PRES, a clinical pattern consistent with systemic inflammatory response syndrome develops with evidence of multiple organ dysfunction syndrome (MODS), including alteration of coagulation (thrombocytopenia), liver function (increased bilirubin), renal function (increased creatinine), pulmonary function, and cardiovascular instability. ${ }^{36}$
Similar features may develop in patients after allo-BMT. The effects of graft-versus-host disease (GVHD) are managed by immune suppression with cyclosporine or tacrolimus (FK-506). Cyclosporine can injure the endothelium. ${ }^{45,46}$ At toxicity, diffuse endothelial dysfunction is often present, termed "bone marrow transplant thrombotic microangiopathy," with development of significant schistocyte counts (exceeding 10\% when severe) and marked elevation of LDH. ${ }^{16,17,47}$ A MODS pattern can develop with systemic or pulmonary edema and ischemic hepatic dysfunction, similar to preeclampsia. ${ }^{48}$

\section{Major PRES-Associated Clinical "Conditions"}

Preeclampsia/Eclampsia. The association of PRES with toxemia of pregnancy is well established. ${ }^{1-3,5,21,24,26,49,50}$ Preeclampsia develops in approximately $5 \%$ of pregnancies and eclampsia, in approximately 1 in 3000 births with current management. ${ }^{43,44}$ Eclampsia develops before gestation in $50 \%$ of patients, interpartum in $25 \%$, and within 48 hours of delivery in $25 \%$. Although most women are hypertensive at toxicity, blood pressure is reported as normal or only minimally elevated in $23 \%$ of patients. ${ }^{39}$ The placenta is thought to be the primary cause of toxemia, with placenta removal and fetal delivery considered curative. ${ }^{43,44}$

"Delayed Eclampsia" (PRES within several weeks after delivery) can occur, and the clinical presentation is often confus- 


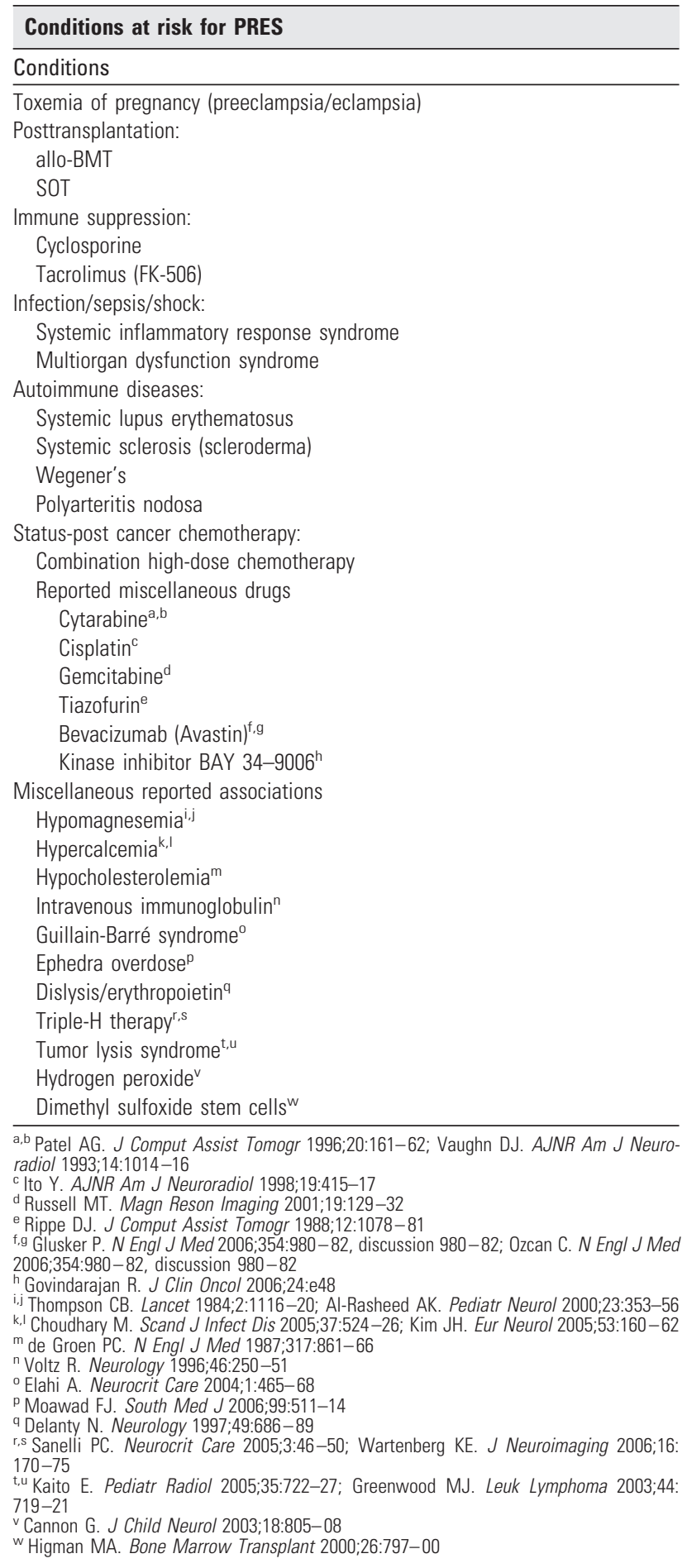

ing. ${ }^{4,51}$ Blood pressure may be normal or mildly elevated, severe headache is common, and conventional angiography is often performed to exclude intracranial aneurysm. In a recently reported case, delayed eclampsia appeared to have been associated with retained placental fragments. ${ }^{52}$ PRES has also been reported 3 weeks following resection and chemotherapy for hydatidiform mole. ${ }^{53}$

Infection/Sepsis/Shock. In infection, sepsis, and shockassociated PRES, gram-positive organisms predominate, and in $40 \%$ of patients, toxicity blood pressure is normal or only minimally increased. ${ }^{36}$ At imaging, vasogenic edema is greater in normotensive patients and lower in severely hypertensive patients; and at MR angiography (MRA), reversible "vasculopathy" (diffuse/focal vasoconstriction) or vessel pruning is noted. ${ }^{36}$ Recent reports note PRES in the setting of post-streptococcal glomerulonephritis, Henoch-Schonlein purpura, and infection-induced hypercoagulable state. ${ }^{54-56}$

Autoimmune Disease. PRES has been identified in patients with systemic lupus erythematosus, Wegener's granulomatosis, systemic sclerosis (scleroderma, Fig 2), and polyarteritis nodosa. ${ }^{15,20,22,27,57-60}$ Detailed accounts of the clinical circumstances surrounding PRES in association with autoimmune disease are infrequent. ${ }^{57-60}$ Patients are commonly managed with intermittent doses of immunosuppression (cyclophosphamide, cyclosporine) for disease control.

Cancer Chemotherapy. PRES is usually encountered after high-dose multidrug cancer therapy, typically in hematopoietic malignancies. ${ }^{61-64} \mathrm{~A}$ variety of cancer chemotherapeutic drugs have also been noted in association with PRES (Table).

Transplantation. PRES is well recognized in the setting of bone marrow or stem cell transplantation. ${ }^{11,17,18,65-68}$ The incidence of PRES after allo-BMT using myeloablative marrow preconditioning and cyclosporine immune suppression is approximately $7 \%-9 \%$ and appears to vary with a preconditioning regimen. ${ }^{11,67,69} \mathrm{~A}$ greater frequency $(16 \%)$ is reported with higher dose myeloablative regimens, and a lower frequency $(3 \%)$ is noted with nonmyeloablative preconditioning. ${ }^{65,69}$ PRES occurs most commonly in the first month after alloBMT, with the remainder during the subsequent year after transplantation. ${ }^{11,40,67,69}$ Reported incidence of PRES with tacrolimus immune suppression appears variable. ${ }^{66,68} \mathrm{~A}$ high incidence of GVHD is also noted in patients with allo-BMT PRES, and a GVHD effect has been suggested. ${ }^{68,70-72}$ Variation in cyclosporine toxicity with human leukocyte antigen match has been noted, and the rate of tacrolimus-associated PRES appears to increase with the degree of graft mismatch. ${ }^{66,67}$

PRES is also noted after SOT. 9,12,13,34,40,73-80 The reported incidence of PRES after SOT varies between $0.4 \%$ and $6 \%{ }^{78,81}$ The onset of PRES varies among subtypes but tends to occur earlier after liver transplantation. ${ }^{81}$ Systemic hypertension was found to be common in patients who develop PRES after renal transplantation but uncommon after heart, lung, or liver transplantation. ${ }^{77,81,82}$ In our experience, transplant rejection and infection often accompany PRES in SOT. ${ }^{83}$ After liver transplantation, PRES typically occurs early (within 2 months after transplantation), blood pressure tends to be normal, and the extent of brain edema is significant. In contrast, patients with kidney transplantation appear to develop PRES late after transplantation, are severely hypertensive, and have significantly less brain edema. ${ }^{83}$

After transplantation, several PRES-related risks coexist. The immune-suppressive drugs cyclosporine/tacrolimus (FK506) inhibit T-cell activation, proliferation, and interleukin-2 production through inhibition of the calcineurin pathway. ${ }^{84,85}$ These drugs are associated with low-level neurotoxicity in $10 \%-40 \%$ of patients (tremors, anxiety, psychiatric dysfunction). ${ }^{37,86}$ Immunosuppressant blood levels do not appear to correlate with severe neurotoxicity or PRES, but immunosuppressant discontinuation or switch usually results in clinical improvement. ${ }^{11,37,67,69,77,86,87}$ Cyclosporine can induce endothelial injury/dysfunction leading to enhanced vasoconstrictive effects (increased endothelin and thrombox- 

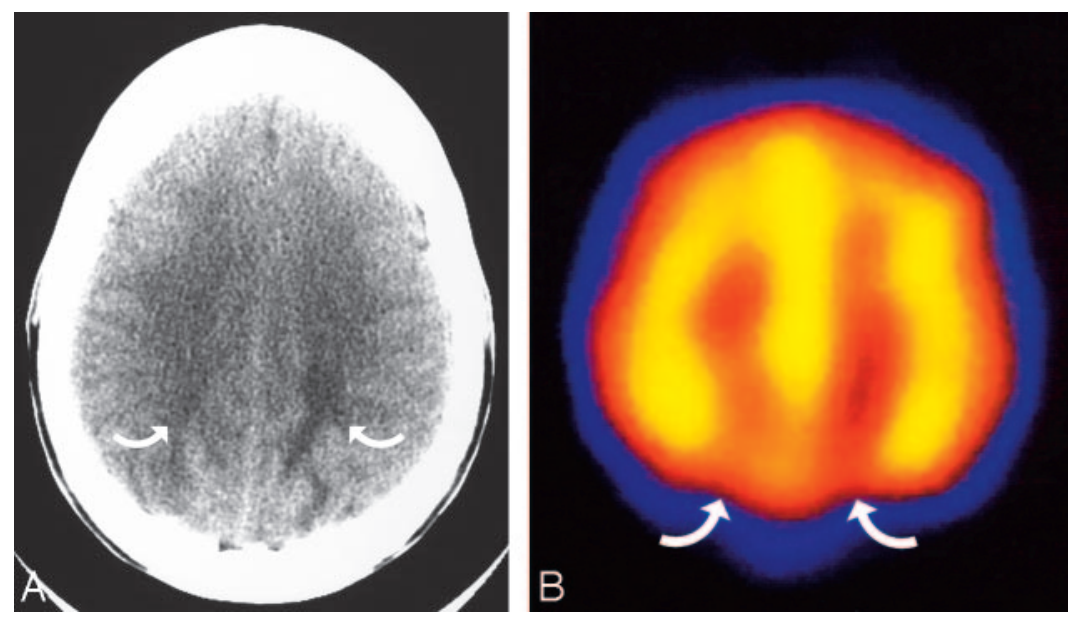

Fig 2. The patient is a 38-year-old woman with scleroderma, severe hypertension $(190 / 110 \mathrm{~mm} \mathrm{Hg}$ ), and acute renal failure with altered mental status that progressed to seizure. A, Axial brain CT image obtained at toxicity demonstrates vasogenic edema in the parietal region bilaterally (curved arrows), consistent with PRES. B, Axial technetiumTc-99m-HMPAO SPECT study performed the following day demonstrates reduced radiopharmaceutical uptake bilaterally in the parietal region (curved arrows), consistent with hypoperfusion.

and organized thrombi. ${ }^{11,101}$ Acute vasculopathy has also been described in a patient with a liver transplant with vessel inflammation and adjacent deep basal ganglia and periventricular infarction. ${ }^{102}$

\section{Advanced Imaging in PRES}

ane, decreased nitric oxide and prostacycline), increased sympathetic activation, and coagulation effects. ${ }^{37,45-47,84,88}$ Immune challenge from the transplant (transplant rejection, GVHD), effects of chemotherapy (preconditioning), and the risks of infection in the immunosuppressed state may further contribute to toxicity. Clearly, a balance exists between adequate immunosuppression and infection risk.

Hypertension. PRES is commonly seen in the setting of hypertension. The upper limits of autoregulation are not typically reached, but moderate-to-severe hypertension is seen in approximately $75 \%$ of patients with PRES. Often termed "hypertensive encephalopathy," the reported imaging patterns can vary. ${ }^{6-8,35,89-93}$ Areas of deep white matter abnormality have been noted, which may overlap with lacunar disease and may relate to the known histologic findings in hypertension. ${ }^{8,93,94}$ Hemispheric PRES patterns have been reported as well as isolated reversible brain stem and cerebellar edema, occasionally resulting in obstructive hydrocephalus. ${ }^{35}$

\section{Recurrent PRES}

Recurrent PRES has been anecdotally reported in severe hypertension and after allo-BMT. ${ }^{66,80}$ In a recent reported series, recurrent PRES was noted in $3(3.8 \%)$ of 78 patients and was associated with sickle-cell disease with infection, allo-BMT with infection, or atypical autoimmune disease and possible viral infection. ${ }^{95}$ Recurrent eclampsia is well recognized with a reported incidence of $\sim 2 \%$ of live births. ${ }^{96}$

\section{Histopathology in PRES}

Histologic evaluation of PRES is uncommon and often obtained late in the course of complex systemic disease. Biopsy/autopsy obtained during acute toxicity demonstrates vasogenic edema, paralleling observations on DWI. ${ }^{17,76,97-99}$ Activated/reactive astrocytes, scattered macrophages, and lymphocytes have been often noted without inflammation, ischemia, or neuronal damage. Late autopsy studies have generally demonstrated evidence of demyelination and myelin pallor along with evidence of ischemia, neuronal anoxic damage, laminar necrosis, or older hemorrhage in the white matter and cortex. ${ }^{11,13,17,100}$

Evidence of acute and chronic vessel injury has been described in late autopsy studies with identification of intimal thickening, segmental vessel narrowing, intimal dissection,

\section{Cerebral Blood Vessels in PRES}

At catheter angiography (CA), diffuse vasoconstriction, focal vasoconstriction, vasodilation, and even a string-of-beads appearance have been noted in PRES, consistent with what is typically described as vasospasm or arteritis (Fig 1C, -D). ${ }^{2,4,14,51,54,103,104}$ Reported blood pressure in most of these patients demonstrated moderate but not severe hypertension (mean arterial pressure $<130 \mathrm{~mm} \mathrm{Hg}$ ). CA in PRES is typically performed in eclampsia, delayed eclampsia, and after cancer chemotherapy, usually in the setting of a clinical presentation in which aneurysm is suspected.

At MRA using a 3D time of flight (TOF) technique, patterns resembling vasculopathy have been noted, with vessel irregularity consistent with focal vasoconstriction/vasodilation and diffuse vasoconstriction (Fig $1 E) .{ }^{17,36,60,95,103,105-108}$ When performed, repeat MRA often demonstrates reversal of the vasculopathy. In normotensive patients, vessels may appear normal or demonstrate pruning of distal intracranial branches, in particular the PCAs. ${ }^{36}$

Abnormal internal carotid or vertebral arteries have, on occasion, been noted in PRES, with intimal irregularity resembling fibromuscular disease demonstrated by CA in delayed eclampsia and dissection noted in PRES on MRA. ${ }^{51,109}$ These CA/MRA features reflect previously described vessel histologic observations. MR venography has tended to be normal in PRES. ${ }^{107}$

\section{Cerebral Blood Flow in PRES}

The state of brain blood flow in PRES remains controversial (Review, Part 2). Vasoconstriction seen by CA in early studies prompted the authors to postulate that reduced brain perfusion led to the imaging features. In contrast, animal studies suggested that experimentally induced hypertension above the autoregulatory limit (mean arterial pressure $>150-160 \mathrm{~mm}$ $\mathrm{Hg}$ ) led to hyperperfusion, breakdown of the blood-brain barrier, and hemispheric edema.

Hyperperfusion was suggested in a single patient with PRES and Wegener's in an early study using technetium Tc99m-hexamethylpropyleneamine oxime (Tc99m-HMPAO) single-photon emission CT (SPECT), with a second patient (eclamptic) demonstrating variable radiotracer distribution. $^{18}$ In a later study, increased Tc99m-HMPAO SPECT activity suggesting hyperperfusion was reported in a single patient with a molar pregnancy and eclampsia. ${ }^{110}$ In patients 

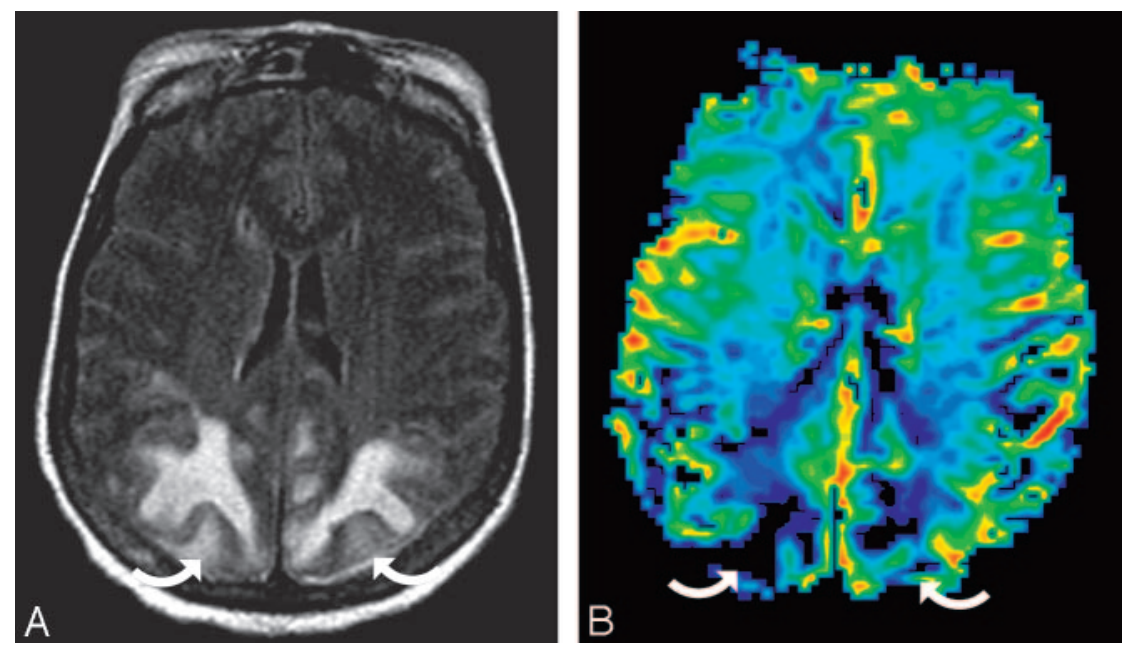

Fig 3. The patient is a 56-year-old woman with a thigh abscess (Klebsiella and Enterococcus species), baseline blood pressure of 156/68 $\mathrm{mm} \mathrm{Hg}$, and multiple organ failure (coagulopathy, acute respiratory distress syndrome, hepatic dysfunction with shock liver, and renal failure). She developed altered mentation and a seizure with toxicity blood pressure 164/75 mm Hg. A, Axial MR image (fluid-attenuated inversion recovery sequence) demonstrates extensive PRES vasogenic edema in the parietal region bilaterally (curved arrows). B, rCBV color map demonstrates severe flow reduction in the parietal region bilaterally (curved arrows), consistent with the regions of PRES imaging abnormality. PRES cortex rCBV relative to the reference cortex is $31 \%$ in the right parietal and $33 \%$ in the left parietal region.

and vasoconstriction may lead to altered integrity of the blood-brain barrier. ${ }^{4,121,122}$

Although commonly cited, several problems exist with the hypertension/hy-

with aneurysmal subarachnoid hemorrhage and vasospasm, Tc99m-HMPAO studies demonstrated patterns of variable perfusion. ${ }^{111}$ Increased radiopharmaceutical activity in Tc99m-HMPAO brain studies has been noted in many circumstances associated with stroke but remains controversial. $^{112}$

In contrast, watershed hypoperfusion has been demonstrated by using Tc99m-HMPAO SPECT in a large series of women with eclampsia, with focal hypoperfusion also noted after chemotherapy and in autoimmune disease (Fig 2). ${ }^{63,113}$ Reduced perfusion has also been demonstrated using MR perfusion (MRP) in PRES (Fig 3). ${ }^{103,114,115}$ Cortex and white matter relative cerebral blood volume ( $\mathrm{rCBV}$ ) has been shown to be reduced moderately in areas of PRES (average, 65\%), when compared with normal uninvolved regions in 2 studies. ${ }^{103,115}$ Comparing anterior-to-posterior hemispheric flow, Brubaker et $\mathrm{al}^{114}$ found that MRP has also demonstrated significant posterior brain hypoperfusion with increased mean transit time, reduced $\mathrm{CBV}$, and reduced cerebral blood flow. ${ }^{114}$ Critical cortex hypoperfusion ( $12.2 \mathrm{~mL} / 100 \mathrm{~g}$ brain per minute) has been demonstrated by stable xenon CT after blood pressure reduction in a child with hypertensive encephalopathy and PRES, which partially reversed with re-established moderate hypertension (mean arterial pressure, $114 \mathrm{~mm} \mathrm{Hg}$ ). ${ }^{116}$

\section{Proton MR Spectroscopy in PRES}

Reduced $N$-acetylaspartate:choline and $N$-acetylaspartate:creatinine ratios have been described by MR spectroscopy in regions of PRES vasogenic edema as well as in unaffected regions. ${ }^{107,117,118}$ Quantitative metabolite assessment in 2 patients demonstrated an absolute reduction of metabolite concentration (considered a dilution effect from vasogenic edema), which corrected in 1 patient on follow-up MR spectroscopy. ${ }^{117}$ Abnormal metabolite ratios may persist. ${ }^{107}$ Lactate has been reported in PRES, and when accompanied by vasoconstriction, a contribution from ischemia has been suggested. $^{42,107}$

\section{The Controversy over the Mechanism of PRES}

The cause of PRES is not yet understood. Hypertension with failed autoregulation and hyperperfusion remains a popular consideration for the developing brain edema. ${ }^{18,92,119,120} \mathrm{Al}-$ ternatively, endothelial dysfunction/injury, hypoperfusion, perperfusion theory. PRES is seen in the absence of hypertension in $20 \%-40 \%$ of patients. ${ }^{17,27,36,39}$ In the remainder, though some degree of hypertension is present, reported blood pressure does not typically reach the limit of autoregulation (mean arterial pressure $>150-160 \mathrm{~mm} \mathrm{Hg}$ ). ${ }^{123}$ Also, several recent studies have noted less vasogenic edema in severely hypertensive patients when compared with normotensive patients, contrary to the expected result if severe hypertension with failed autoregulation was the mechanism behind PRES. ${ }^{36,103}$ The biologic observations (strengths/weaknesses) related to both theories will be reviewed in detail in Part 2.

\section{Conclusion}

PRES develops in patients with complex systemic conditions such as eclampsia, after transplantation, in infection/sepsis/ shock and autoimmune disease, and after cancer chemotherapy. Hypertension is absent in $\sim 25 \%$ of patients and, when present, does not typically reach the level of failed autoregulation. The imaging appearance typically demonstrates symmetric vasogenic edema with several characteristic patterns, generally representing a distribution between lateral and medial cerebral arterial branches (ie, a watershed distribution). Vasculopathy is commonly identified by CA or MRA, and most studies have demonstrated reduced brain perfusion in regions of PRES. The mechanism responsible for the imaging appearance remains unclear and controversial.

\section{References}

1. Colosimo C Jr, Fileni A, Moschini M, et al. CT findings in eclampsia. Neuroradiology 1985;27:313-17

2. Lewis $\mathrm{LK}$, Hinshaw DB Jr, Will AD, et al. CT and angiographic correlation of severe neurological disease in toxemia of pregnancy. Neuroradiology 1988;30:59-64

3. Naheedy MH, Biller J, Schiffer M, et al. Toxemia of pregnancy: cerebral CT findings. J Comput Assist Tomogr 1985;9:497-501

4. Trommer BL, Homer D, Mikhael MA. Cerebral vasospasm and eclampsia. Stroke 1988;19:326-29

5. Waldron RL 2nd, Abbott DC, Vellody D, et al. Computed tomography in preeclampsia-eclampsia syndrome. AJNR Am J Neuroradiol 1985;6:442-43

6. Fisher M, Maister B, Jacobs R. Hypertensive encephalopathy: diffuse reversible white matter CT abnormalities. Ann Neurol 1985;18:268-70

7. Rail DL, Perkin GD. Computerized tomographic appearance of hypertensive encephalopathy. Arch Neurol 1980;37:310-11

8. Weingarten K, Barbut D, Filippi C, et al. Acute hypertensive encephalopathy: findings on spin-echo and gradient-echo MR imaging. AJR Am J Roentgenol 1994;162:665-70

9. de Groen PC, Aksamit AJ, Rakela J, et al. Central nervous system toxicity after 
liver transplantation: the role of cyclosporine and cholesterol. $N$ Engl J Med 1987;317:861-66

10. Ghalie R, Fitzsimmons WE, Bennett D, et al. Cortical blindness: a rare complication of cyclosporine therapy. Bone Marrow Transplant 1990;6:147-49

11. Reece DE, Frei-Lahr DA, Shepherd JD, et al. Neurologic complications in allogeneic bone marrow transplant patients receiving cyclosporin. Bone Marrow Transplant 1991;8:393-401

12. Truwit CL, Denaro CP, Lake JR, et al. MR imaging of reversible cyclosporin A-induced neurotoxicity. AJNR Am J Neuroradiol 1991;12:651-59

13. Wilson SE, de Groen PC, Aksamit AJ, et al. Cyclosporin A-induced reversible cortical blindness. J Clin Neuroophthalmol 1988;8:215-20

14. Will $\mathrm{AD}$, Lewis $\mathrm{KL}$, Hinshaw $\mathrm{DB}$, et al. Cerebral vasoconstriction in toxemia. Neurology 1987;37:1555-57

15. Hinchey J, Chaves C, Appignani B, et al. A reversible posterior leukoencephalopathy syndrome. N Engl J Med 1996;334:494-500

16. Bartynski WS, Grabb BC, Zeigler Z, et al. Watershed imaging features and clinical vascular injury in cyclosporin A neurotoxicity. J Comput Assist Tomogr 1997;21:872-80

17. Bartynski WS, Zeigler Z, Spearman MP, et al. Etiology of cortical and white matter lesions in cyclosporin-A and FK-506 neurotoxicity. AJNR Am J Neuroradiol 2001;22:1901-14

18. Schwartz RB, Bravo SM, Klufas RA, et al. Cyclosporine neurotoxicity and its relationship to hypertensive encephalopathy: CT and MR findings in 16 cases. AJR Am J Roentgenol 1995;165:627-31

19. Ay H, Buonanno FS, Schaefer PW, et al. Posterior leukoencephalopathy without severe hypertension: utility of diffusion-weighted MRI. Neurology 1998;51:1369-76

20. Covarrubias DJ, Luetmer PH, Campeau NG. Posterior reversible encephalopathy syndrome: prognostic utility of quantitative diffusion-weighted MR images. AJNR Am J Neuroradiol 2002;23:1038-48

21. Koch S, Rabinstein A, Falcone S, et al. Diffusion-weighted imaging shows cytotoxic and vasogenic edema in eclampsia. AJNR Am J Neuroradiol 2001;22:1068-70

22. Mukherjee P, McKinstry RC. Reversible posterior leukoencephalopathy syndrome: evaluation with diffusion-tensor MR imaging. Radiology 2001;219:756-65

23. Provenzale JM, Petrella JR, Cruz LC Jr, et al. Quantitative assessment of diffusion abnormalities in posterior reversible encephalopathy syndrome. AJNR Am J Neuroradiol 2001;22:1455-61

24. Schaefer PW, Buonanno FS, Gonzalez RG, et al. Diffusion-weighted imaging discriminates between cytotoxic and vasogenic edema in a patient with eclampsia. Stroke 1997;28:1082-85

25. Dahmus MA, Barton JR, Sibai BM. Cerebral imaging in eclampsia: magnetic resonance imaging versus computed tomography. Am J Obstet Gynecol 1992;167:935-41

26. Raroque HG Jr, Orrison WW, Rosenberg GA. Neurologic involvement in toxemia of pregnancy: reversible MRI lesions. Neurology 1990;40:167-69

27. Bartynski WS, Boardman JF. Distinct imaging patterns and lesion distribution in posterior reversible encephalopathy syndrome. AJNR Am J Neuroradiol 2007;28:1320-27

28. Oliverio PJ, Restrepo L, Mitchell SA, et al. Reversible tacrolimus-induced neurotoxicity isolated to the brain stem. AJNR Am J Neuroradiol 2000;21:1251-54

29. Casey SO, Truwit CL. Pontine reversible edema: a newly recognized imaging variant of hypertensive encephalopathy? AJNR Am J Neuroradiol 2000;21:243-45

30. de Seze J, Mastain B, Stojkovic T, et al. Unusual MR findings of the brain stem in arterial hypertension. AJNR Am J Neuroradiol 2000;21:391-94

31. Keswani SC, Wityk R. Don't throw in the towel! A case of reversible coma. J Neurol Neurosurg Psychiatry 2002;73:83-84

32. McKinney AM, Short J, Truwit CL, et al. Posterior reversible encephalopathy syndrome: incidence of atypical regions of involvement and imaging findings. AJR Am J Roentgenol 2007;189:904-12

33. Keyserling HF, Provenzale JM. Atypical imaging findings in a near-fatal case of posterior reversible encephalopathy syndrome in a child. AJR Am J Roentgenol 2007;188:219-21

34. Nussbaum ES, Maxwell RE, Bitterman PB, et al. Cyclosporine A toxicity presenting with acute cerebellar edema and brainstem compression: case report. J Neurosurg 1995;82:1068-70

35. Lin KL, Hsu WC, Wang HS, et al. Hypertension-induced cerebellar encephalopathy and hydrocephalus in a male. Pediatr Neurol 2006;34:72-75

36. Bartynski WS, Boardman JF, Zeigler ZR, et al. Posterior reversible encephalopathy syndrome in infection, sepsis, and shock. AJNR Am J Neuroradiol 2006;27:2179-90

37. Gijtenbeek JM, van den Bent MJ, Vecht CJ. Cyclosporine neurotoxicity: a review. J Neurol 1999;246:339-46

38. Garg RK. Posterior leukoencephalopathy syndrome. Postgrad Med J 2001;77:24-28

39. Sibai BM. Eclampsia. VI. Maternal-perinatal outcome in 254 consecutive cases. Am J Obstet Gynecol 1990;163:1049-54, discussion 1054-55

40. Furukawa M, Terae S, Chu BC, et al. MRI in seven cases of tacrolimus (FK-
506) encephalopathy: utility of FLAIR and diffusion-weighted imaging. $\mathrm{Neu}$ roradiology 2001;43:615-21

41. Ishikura K, Ikeda M, Hamasaki Y, et al. Posterior reversible encephalopathy syndrome in children: its high prevalence and more extensive imaging findings. Am J Kidney Dis 2006;48:231-38

42. Kwon S, Koo J, Lee S. Clinical spectrum of reversible posterior leukoencephalopathy syndrome. Pediatr Neurol 2001;24:361-64

43. Hypertensive disorders of pregnancy. In: Cunningham FG, Gant NF, Leveno KJ, eds. Williams Obstetrics. 21st ed. New York: McGraw Hill; 2001:567-618

44. Dekker GA, Sibai BM. Etiology and pathogenesis of preeclampsia: current concepts. Am J Obstet Gynecol 1998;179:1359-75

45. Holler E, Kolb HJ, Hiller E, et al. Microangiopathy in patients on cyclosporine prophylaxis who developed acute graft-versus-host disease after HLA-identical bone marrow transplantation. Blood 1989;73:2018-24

46. Zoja C, Furci L, Ghilardi F, et al. Cyclosporin-induced endothelial cell injury. Lab Invest 1986;55:455-62

47. Zeigler ZR, Shadduck RK, Nemunaitis J, et al. Bone marrow transplant-associated thrombotic microangiopathy: a case series. Bone Marrow Transplan 1995;15:247-53

48. Haire WD. The multiple organ dysfunction syndrome in cancer patients un dergoing hematopoietic stem cell transplantation. Semin Thromb Hemost 1999;25:223-37

49. Sanders TG, Clayman DA, Sanchez-Ramos L, et al. Brain in eclampsia: MR imaging with clinical correlation. Radiology 1991;180:475-78

50. Schwartz RB, Feske SK, Polak JF, et al. Preeclampsia-eclampsia: clinical and neuroradiographic correlates and insights into the pathogenesis of hypertensive encephalopathy. Radiology 2000;217:371-76

51. Bartynski WS, Sanghvi A. Neuroimaging of delayed eclampsia: report of 3 cases and review of the literature. J Comput Assist Tomogr 2003;27:699-713

52. Delefosse D, Samain E, Helias A, et al. Late onset of cortical blindness in a patient with severe preeclampsia related to retained placental fragments. Anesthesiology 2003;98:261-63

53. Malow BA, Sandson TA, Schwartz RB. Reversible MRI lesions in eclampsia with hydatidiform mole. Neurology 1990;40:1471-72

54. Aeby A, David P, Fricx C, et al. Posterior reversible encephalopathy syndrome revealing acute post-streptococcal glomerulonephritis. J Child Neurol 2006;21:250-51

55. Ozcakar ZB, Ekim M, Fitoz S, et al. Hypertension induced reversible posterior leukoencephalopathy syndrome: a report of two cases. Eur J Pediat 2004; 163:728-30

56. Yano Y, Kario K, Fukunaga T, et al. A case of reversible posterior leukoencephalopathy syndrome caused by transient hypercoagulable state induced by infection. Hypertens Res 2005;28:619-23

57. Kur JK, Esdaile JM. Posterior reversible encephalopathy syndrome: an underrecognized manifestation of systemic lupus erythematosus. J Rheumato 2006;33:2178-83

58. Magnano MD, Bush TM, Herrera I, et al. Reversible posterior leukoencephalopathy in patients with systemic lupus erythematosus. Semin Arthritis Rheum 2006;35:396-402

59. Primavera A, Audenino D, Mavilio N, et al. Reversible posterior leucoencephalopathy syndrome in systemic lupus and vasculitis. Ann Rheum Dis 2001;60:534-37

60. Thaipisuttikul I, Phanthumchinda K. Recurrent reversible posterior leukoencephalopathy in a patient with systemic lupus erythematosus. J Neurol 2005;252:230-31

61. Cooney MJ, Bradley WG, Symko SC, et al. Hypertensive encephalopathy: complication in children treated for myeloproliferative disorders-report of three cases. Radiology 2000;214:711-16

62. Morris EB, Laningham FH, Sandlund JT, et al. Posterior reversible encephalopathy syndrome in children with cancer. Pediatr Blood Cancer 2007;48:152-59

63. Sanchez-Carpintero R, Narbona J, Lopez de Mesa R, et al. Transient posterior encephalopathy induced by chemotherapy in children. Pediatr Neurol 2001;24:145-48

64. Pihko H, Tyni T, Virkola K, et al. Transient ischemic cerebral lesions during induction chemotherapy for acute lymphoblastic leukemia. J Pediatr 1993;123:718-24

65. Kishi Y, Miyakoshi S, Kami M, et al. Early central nervous system complications after reduced-intensity stem cell transplantation. Biol Blood Marrow Transplant 2004;10:561-68

66. Wong R, Beguelin GZ, de Lima M, et al. Tacrolimus-associated posterior reversible encephalopathy syndrome after allogeneic haematopoietic stem cell transplantation. Br J Haematol 2003;122:128-34

67. Zimmer WE, Hourihane JM, Wang HZ, et al. The effect of human leukocyte antigen disparity on cyclosporine neurotoxicity after allogeneic bone marrow transplantation. AJNR Am I Neuroradiol 1998;19:601-08, discussion $609-10$

68. Kanekiyo T, Hara J, Matsuda-Hashii Y, et al. Tacrolimus-related encephalopathy following allogeneic stem cell transplantation in children. Int J Hemato 2005;81:264-68

69. Bartynski WS, Zeigler ZR, Shadduck RK, et al. Pretransplantation condition- 
ing influence on the occurrence of cyclosporine or FK-506 neurotoxicity in allogeneic bone marrow transplantation. AJNR Am J Neuroradiol 2004;25:261-69

70. Bartynski WS, Zeigler ZR, Shadduck RK, et al. Variable incidence of cyclosporine and FK-506 neurotoxicity in hematopoeitic malignancies and marrow conditions after allogeneic bone marrow transplantation. Neurocrit Care 2005;3:33-45

71. Chohan R, Vij R, Adkins D, et al. Long-term outcomes of allogeneic stem cell transplant recipients after calcineurin inhibitor-induced neurotoxicity. $\mathrm{BrJ}$ Haematol 2003;123:110-13

72. Provenzale JM, Graham ML. Reversible leukoencephalopathy associated with graft-versus-host disease: MR findings. AJNR Am J Neuroradiol 1996;17:1290-94

73. Jarosz JM, Howlett DC, Cox TC, et al. Cyclosporine-related reversible posterior leukoencephalopathy: MRI. Neuroradiology 1997;39:711-15

74. Small SL, Fukui MB, Bramblett GT, et al. Immunosuppression-induced leukoencephalopathy from tacrolimus (FK506). Ann Neurol 1996;40:575-80

75. Appignani BA, Bhadelia RA, Blacklow SC, et al. Neuroimaging findings in patients on immunosuppressive therapy: experience with tacrolimus toxicity. AJR Am J Roentgenol 1996;166:683-88

76. Lanzino G, Cloft H, Hemstreet MK, et al. Reversible posterior leukoencephalopathy following organ transplantation: description of two cases. Clin Neurol Neurosurg 1997;99:222-26

77. Shimono $\mathrm{T}$, Miki $\mathrm{Y}$, Toyoda $\mathrm{H}$, et al. MR imaging with quantitative diffusion mapping of tacrolimus-induced neurotoxicity in organ transplant patients. Eur Radiol 2003;13:986-93

78. Besenski N, Rumboldt Z, Emovon O, et al. Brain MR imaging abnormalities in kidney transplant recipients. AJNR Am J Neuroradiol 2005;26:2282-89

79. Parvex P, Pinsk M, Bell LE, et al. Reversible encephalopathy associated with tacrolimus in pediatric renal transplants. Pediatr Nephrol 2001;16:537-42

80. Reinohs M, Straube T, Baum P, et al. Recurrent reversible cerebral edema after long-term immunosuppression with tacrolimus. J Neurol 2002;249:780-81

81. Singh N, Bonham A, Fukui M. Immunosuppressive-associated leukoencephalopathy in organ transplant recipients. Transplantation 2000;69:467-72

82. Wijdicks EF. Neurotoxicity of immunosuppressive drugs. Liver Transpl 2001;7:937-42

83. Bartynski WS, Tan HP, Boardman JF, et al. Posterior reversible encephalopathy syndrome after solid organ transplantation. AJNR Am J Neuroradiol 2008;29:924-30

84. Ramanathan V, Helderman JH. Cyclosporine formulations. In: Sayegh M, Remuzzi G, eds. Current and Future Immunosuppressive Therapies Following Transplantation. The Netherlands: Kluwer Academic; 2001:111-21

85. Shapiro R. Tacrolimus. In: Sayegh M, Remuzzi G, eds. Current and Future Immunosuppressive Therapies Following Transplantation. The Netherlands: Kluwer Academic; 2001:123-42

86. Wijdicks EFM. Neurologic manifestations of immunosuppressive agents. In: Wijdicks EFM, ed. Neurologic Complications in Organ Transplant Recipients. Boston: Butterworth-Heinemann; 1999:127-40

87. Furlong T, Storb R, Anasetti C, et al. Clinical outcome after conversion to FK 506 (tacrolimus) therapy for acute graft-versus-host disease resistant to cyclosporine or for cyclosporine-associated toxicities. Bone Marrow Transplant 2000;26:985-91

88. Kon V, Sugiura M, Inagami T, et al. Role of endothelin in cyclosporine-induced glomerular dysfunction. Kidney Int 1990;37:1487-91

89. Hauser RA, Lacey DM, Knight MR. Hypertensive encephalopathy: magnetic resonance imaging demonstration of reversible cortical and white matter lesions. Arch Neurol 1988;45:1078-83

90. Jones BV, Egelhoff JC, Patterson RJ. Hypertensive encephalopathy in children. AJNR Am J Neuroradiol 1997;18:101-06

91. Kwong YL, Yu YL, Lam KS, et al. CT appearance in hypertensive encephalopathy. Neuroradiology 1987;29:215

92. Schwartz RB, Jones KM, Kalina P, et al. Hypertensive encephalopathy: findings on CT, MR imaging, and SPECT imaging in 14 cases. AJR Am J Roentgenol 1992;159:379-83

93. Weingarten KL, Zimmerman RD, Pinto RS, et al. Computed tomographic changes of hypertensive encephalopathy. AJNR Am J Neuroradiol 1985;6:395-98

94. Chester EM, Agamanolis DP, Banker BQ, et al. Hypertensive encephalopathy: a clinicopathologic study of 20 cases. Neurology 1978;28:928-39

95. Sweany JM, Bartynski WS, Boardman JF. "Recurrent" posterior reversible encephalopathy syndrome: report of 3 cases-PRES can strike twice! J Comput Assist Tomogr 2007;31:148-56
96. Sibai BM, Sarinoglu C, Mercer BM. Eclampsia. VII. Pregnancy outcome after eclampsia and long-term prognosis. Am J Obstet Gynecol 1992;166(6 Pt 1): 1757-61, discussion 1761-63

97. Schiff D, Lopes MB. Neuropathological correlates of reversible posterior leukoencephalopathy. Neurocrit Care 2005;2:303-05

98. Thyagarajan GK, Cobanoglu A, Johnston W. FK506-induced fulminant leukoencephalopathy after single-lung transplantation. Ann Thorac Surg 1997;64:1461-64

99. Velu T, Debusscher L, Stryckmans PA. Cyclosporin-associated fatal convulsions. Lancet 1985;1:219

100. Vaughn DJ, Jarvik JG, Hackney D, et al. High-dose cytarabine neurotoxicity: MR findings during the acute phase. AJNR Am J Neuroradiol 1993;14:1014-16

101. Koide T, Yamada M, Takahashi T, et al. Cyclosporine A-associated fatal central nervous system angiopathy in a bone marrow transplant recipient: an autopsy case. Acta Neuropathol 2000;99:680-84

102. Pizzolato GP, Sztajzel R, Burkhardt K, et al. Cerebral vasculitis during FK 506 treatment in a liver transplant patient. Neurology 1998;50:1154-57

103. Bartynski WS, Boardman JF. Catheter angiography, MR angiography, and MR perfusion in posterior reversible encephalopathy syndrome. AJNR Am J Neuroradiol. 2008;29:447-55

104. Geraghty JJ, Hoch DB, Robert ME, et al. Fatal puerperal cerebral vasospasm and stroke in a young woman. Neurology 1991;41:1145-47

105. Ito $\mathrm{T}$, Sakai $\mathrm{T}$, Inagawa $\mathrm{S}$, et al. MR angiography of cerebral vasospasm in preeclampsia. AJNR Am J Neuroradiol 1995;16:1344-46

106. Lin JT, Wang SJ, Fuh JL, et al. Prolonged reversible vasospasm in cyclosporin A-induced encephalopathy. AJNR Am J Neuroradiol 2003;24:102-04

107. Sengar AR, Gupta RK, Dhanuka AK, et al. MR imaging, MR angiography, and MR spectroscopy of the brain in eclampsia. AJNR Am J Neuroradio 1997;18:1485-90

108. Shbarou RM, Chao NJ, Morgenlander JC. Cyclosporin A-related cerebral vasculopathy. Bone Marrow Transplant 2000;26:801-04

109. Mellion ML, Rizvi S. Spontaneous bilateral carotid artery dissection and posterior reversible encephalopathy syndrome. Neurology 2005;65:1990

110. Apollon KM, Robinson JN, Schwartz RB, et al. Cortical blindness in severe preeclampsia: computed tomography, magnetic resonance imaging, and single-photon-emission computed tomography findings. Obstet Gyneco 2000;95:1017-19

111. Lewis DH, Eskridge JM, Newell DW, et al. Brain SPECT and the effect of cerebral angioplasty in delayed ischemia due to vasospasm. J Nucl Med 1992;33:1789-96

112. Sugawara $Y$, Ueda T, Kikuchi T, et al. Hyperactivity of 99mTc-HMPAO within 6 hours in patients with acute ischemic stroke. J Nucl Med 2001;42:1297-302

113. Naidu K, Moodley J, Corr P, et al. Single photon emission and cerebral computerised tomographic scan and transcranial Doppler sonographic findings in eclampsia. Br J Obstet Gynaecol 1997;104:1165-72

114. Brubaker LM, Smith JK, Lee YZ, et al. Hemodynamic and permeability changes in posterior reversible encephalopathy syndrome measured by dynamic susceptibility perfusion-weighted MR imaging. AJNR Am J Neuroradiol 2005;26:825-30

115. Engelter ST, Petrella JR, Alberts MJ, et al. Assessment of cerebral microcirculation in a patient with hypertensive encephalopathy using MR perfusion imaging. AJR Am J Roentgenol 1999;173:1491-93

116. Casey SO, McKinney A, Teksam M, et al. CT perfusion imaging in the management of posterior reversible encephalopathy. Neuroradiology 2004;46:272-76

117. Eichler FS, Wang P, Wityk RJ, et al. Diffuse metabolic abnormalities in reversible posterior leukoencephalopathy syndrome. AJNR Am J Neuroradiol 2002;23:833-37

118. Russell MT, Nassif AS, Cacayorin ED, et al. Gemcitabine-associated posterior reversible encephalopathy syndrome: MR imaging and MR spectroscopy findings. Magn Reson Imaging 2001;19:129-32

119. Strandgaard S, Olesen J, Skinhoj E, et al. Autoregulation of brain circulation in severe arterial hypertension. BMJ 1973;1:507-10

120. Dinsdale HB. Hypertensive encephalopathy. Neurol Clin 1983;1:3-16

121. Coughlin WF, McMurdo SK, Reeves T. MR imaging of postpartum cortical blindness. J Comput Assist Tomogr 1989;13:572-76

122. Toole JF. Lacunar syndromes and hypertensive encephalopathy. In: Toole JF, ed. Cerebrovascular Disorders. 5th ed. New York: Raven; 1999:342-55

123. Zwienenberg-Lee M, Muizelaar JP. Clinical pathophysiology of traumatic brain injury. In: HR W, ed. Youmans Neurological Surgery. 5th ed. Philadelphia: Saunders; 2004:5039-64 